\title{
O Tao na Medicina de Família e Comunidade: Relações entre Acupuntura e o Método Clínico Centrado na Pessoa
}

\section{The Tao in Family and Community Medicine: relations between Acupuncture and the Person-Centered Clinical Method}

\section{El Tao en la Medicina da la Familia y Comunidad: Relaciones entre Acupuntura y el Método Clínico Centrado en la Persona}

\author{
Aarão Carajás Dias dos Santos ${ }^{1} \mathbb{D}$, Isabel Brandão Correia² ${ }^{\mathbb{D}}$, Rubens Cavalcanti Silva ${ }^{3}$ \\ ${ }^{1}$ Prefeitura do Recife. Recife, PE, Brasil. \\ ${ }^{2}$ Secretaria de Saúde do Recife. Recife, PE, Brasil. \\ ${ }^{3}$ Universidade de Pernambuco; Prefeitura da Cidade do Recife; Universidade do Estado do Rio de Janeiro. Recife, PE, Brasil.
}

\section{Resumo}

Objetivo: Compreender a extensão dos componentes do Método Clínico Centrado na Pessoa na prática da acupuntura a partir da percepção dos usuários. Métodos: Por meio de uma pesquisa qualitativa com grupo focal, buscou-se entender como a acupuntura faz a pessoa perceber suas experiências de saúde e doença; intensifica a percepção da pessoa enquanto ser integral; viabiliza a pessoa se sentir participante do processo de cuidado; auxilia na intensificação da relação médico-pessoa. Resultados: Emergiram temas que versavam sobre emancipação, autoconhecimento, integralidade, vínculos e afetos, que foram sistematizados nas categorias: A prática integrada do MCCP/MTC produzindo rizomas; Unidade mente-corpo no contexto do cuidado; Percepção de uma anatomia emocional e MCCP E MTC como reconfiguradoras do Circuito dos Afetos. Conclusões: O estudo reflete, a partir da percepção dos usuários, a utilização dos conhecimentos advindos de outras racionalidades para potencializar o cuidado realizado na Atenção Primária à Saúde.

Palavras-chave: Terapia por Acupuntura; Medicina de Família e Comunidade; Assistência Centrada no Paciente

Como citar: Santos ACD, Correia IB, Silva RC. O Tao na Medicina de Família e Comunidade: Relações entre Acupuntura e o Método Clínico Centrado na Pessoa. Rev Bras Med Fam Comunidade. 2019;14(41):1624. https://doi.org/10.5712/rbmfc14(41)1624
Autor correspondente: Aarão Carajás Dias dos Santos. E-mail: aaraocarajas@yahoo.com.br Fonte de financiamento: declaram não haver.

Parecer CEP: 1.940.117 (HUOC/PROCAPE), aprovado em 23/02/2017.

Procedência e revisão por pares: revisado por pares. Recebido em: 18/09/2017. Aprovado em: 28/02/2019 


\begin{abstract}
Objective: To understand the extent of the components of the Person-Centered Clinical Method relates to the practice of acupuncture, based on the perception of the users. Methods: By a qualitative research with focus group, this study aimed to understand how acupuncture makes the person to perceive their health and illness experience; intensifies the person's perception as an integral being; allows for the person to participate in the process of care; strengths the physician-person relationship. Results: The themes that emerged included emancipation, self-knowledge, completeness, bonds and affections. They were organized in categories: Integrated MCCP/MTC practice producing rhizomes; Mind-body unity in the context of care; Perception of an emotional anatomy and MCCP and MTC reconfiguring the Circuit of Affections. Conclusions: The study reflects, from the perception of the users, the use of the knowledge that derives from other rationalities to enhance the care performed in Primary Health Care.
\end{abstract}

Keywords: Acupuncture Therapy; Family Practice; Patient-Centered Care

\title{
Resumen
}

Objetivo: Comprender la extensión de los componentes del Método Clínico Centrado en la Persona en la práctica de la acupuntura, a partir de la percepción de los usuarios. Métodos: A través de una investigación cualitativa con grupo focal, buscamos comprender cómo la acupuntura hace que la persona perciba sus experiencias de salud y enfermedad; Intensifica la percepción de la persona como un ser integral; Permite que la persona se sienta involucrada en el proceso de cuidados; Esto ayuda a intensificar la relación médico-persona. Resultados: Surgieron temas relacionados a la emancipación, autoconocimiento, integralidad, vínculos y afecciones, que se sistematizaron en las categorías: práctica integrada MCCP/TCM produciendo rizomas; Unidad mente-cuerpo en el contexto del cuidado; Percepción de una anatomía emocional y MCCP y MTC como nuevos configuradores del Circuito de Afectos. Conclusiones: El estudio refleja, a partir de la percepción de los usuarios, el uso de conocimientos advenidos de otras racionalidades para mejorar el cuidado realizado en la Atención Primaria a la Salud.

Palabras clave: Terapia por Acupuntura; Medicina Familiar y Comunitaria; Atención Dirigida al Paciente

\section{Introdução}

A Medicina Tradicional Chinesa (MTC) é uma representante da ontologia do Tao que se difere da ocidental na medida em que apresenta uma visão holística e indissociável do homem com a natureza. Ela faz parte de um grupo denominado de Práticas Integrativas e Complementares (PIC), como designa o Ministério da Saúde. ${ }^{1}$ Sua inclusão no Sistema Único de Saúde (SUS) é apropriada aos diversos níveis de atenção à saúde, mas pode ter maior inserção na Atenção Primária à Saúde (APS), em que o cuidado acontece de forma mais humanizada, integral e continuada. ${ }^{2}$

O desenvolvimento das PIC nos Sistemas de Saúde públicos universais é favorável e seu crescimento é incontestável nas últimas décadas. Desde a Conferência Internacional de Alma Ata, realizada em 1978, a Organização Mundial de Saúde recomenda a seus países membros a inclusão das PIC nos Sistemas Públicos de Saúde. ${ }^{3}$

Nesse mesmo cenário de prática, insere-se o Método Clínico Centrado na Pessoa (MCCP), que viabiliza um modelo de cuidado integral de abordagem às necessidades e às expectativas de médicos e pessoas, abrindo caminho para uma consulta mais adequada à realidade da APS. ${ }^{4}$

O MCCP foi sistematizado a partir de estudos de um grupo de pesquisadores da Universidade de Western Ontário, no Canadá, e busca compreender a pessoa e sua doença por meio do acesso harmônico das demandas do médico e da pessoa assistida. Atualmente, é composto por quatro componentes: Explorando a saúde, a doença e a experiência com a doença; Entendendo a pessoa como um todo; Elaborando um Projeto comum de cuidado; e Intensificando a relação médico-pessoa. ${ }^{5}$

A acupuntura, dentro desse universo das práticas, constitui um canal importante, pois a utilização de outra racionalidade fortalece a clínica tradicional na medida em que amplia a resolutividade da APS. 
Dialoga ainda com o MCCP, pois apresenta um modelo amplo de compreensão do sujeito doente e do processo terapêutico, fornecendo um ambiente potencialmente emancipatório e com menos iatrogenias. ${ }^{2}$

Outro fator importante é que a acupuntura também atua na dimensão subjetiva, na promoção da saúde, na prevenção de doenças e na reabilitação, tratando da condição humana para além da afecção, em busca do equilíbrio corpo-mente-espírito. ${ }^{6}$

Essa forma de gerir a saúde ocorre pelo fato da MTC ter em sua racionalidade um olhar ampliado sobre as condições em que os sujeitos se encontram, baseando seu diagnóstico pela análise de fenômenos naturais que podem estar em desequilíbrio, o que gera o processo de adoecimento. Assim, a acupuntura pode atuar em múltiplas condições patológicas que variam desde uma lesão física e estrutural, passando por uma dor crônica vaga, até fatores emocionais. ${ }^{7}$

Soma-se a essa dinâmica de crescimento das PIC a concepção da categoria denominada Racionalidades Médicas, que engloba a biomedicina como mais um sistema de cura dentre vários existentes, o que fornece uma nova perspectiva de abordagem contra-hegemônica perante o sistema de saúde vigente. ${ }^{8}$

A visão holística da prática da MTC se aproxima do MCCP inserido na APS. Essa ligação parece fortalecer a promoção da saúde, a prevenção de doenças, o tratamento e a reabilitação dentro da APS. ${ }^{9}$

A partir da identificação de que a Acupuntura e o MCCP são pautados no paradigma integralista e que há indícios de que a soma das racionalidades é potencializadora do cuidado aos usuários do SUS, este estudo objetivou examinar a relação entre a prática da acupuntura e o MCCP a partir das percepções dos usuários acompanhados em uma unidade da APS.

\section{Métodos}

Realizou-se um estudo de natureza qualitativa, com usuários de uma Unidade de Saúde da Família de uma capital nordestina, visando-se compreender a extensão dos componentes do Método Clínico Centrado na Pessoa na prática da acupuntura. Parte-se do pressuposto de que o papel da pesquisa qualitativa é tentar representar a realidade subjacente que pode ser estudada, mais do que buscar uma dita "verdade" absoluta. ${ }^{10}$

Para se aproximar de uma compreensão dessa realidade, utilizou-se a técnica de pesquisa de grupo focal, de modalidade exploratória. Tal modalidade visa desenvolver ideias e hipóteses acerca de um determinado objeto de pesquisa. ${ }^{11}$ Buscando-se compreender a extensão dos componentes do Método Clínico Centrado na Pessoa na prática da acupuntura a partir da percepção dos usuários, os sujeitos de pesquisa foram selecionados a partir de critérios pré-determinados, com a intenção de se constituir um grupo homogêneo.

Partiu-se do pressuposto de que "grupos homogêneos, por serem compostos por indivíduos que compartilham de uma experiência comum, facilitam a troca de ideias e experiências". ${ }^{12} \mathrm{E}$ que "indivíduos pertencentes a um contexto semelhante promovem, no grupo, um senso de segurança para expressões de preocupações e conflitos." 12

A partir desses pressupostos, foram definidos os critérios para a seleção da amostra: pessoas cuidadas por um profissional, o pesquisador principal, por meio de uma abordagem centrada na pessoa, com a utilização do MCCP; e que haviam realizado sessões de acupuntura como parte do plano de cuidados estabelecido. Como atualmente não existe um consenso sobre o número mínimo de sessões necessárias 
para tratamento com acupuntura e sabendo-se que mudanças já podem ser percebidas desde a primeira sessão, foi estabelecido, por consenso entre os três pesquisadores, o número mínimo de cinco sessões de acupuntura para cada usuário envolvido no estudo. A partir desses critérios, chegou-se a amostra da população da pesquisa.

Uma vez que "é difícil, e mesmo impossível, descrever o procedimento de amostragem, sem fazer referência ao projeto de construção progressiva do objeto como um todo"13 e que, nos estudos qualitativos, "enfatizam-se mais as relações entre amostra e objeto do que as regras técnicas de amostragem", ${ }^{13}$ faz-se necessário descrever como os sujeitos da pesquisa foram selecionados.

Após o desenvolvimento do projeto desta pesquisa, um dos pesquisadores, o principal, que estava em processo de formação em acupuntura, passou a registrar todas as pessoas que realizavam sessões de tal prática no processo de cuidado na unidade de saúde onde atuava. Seguindo-se o cronograma do projeto de pesquisa, no mês em que se planejou realizar o grupo focal, 12 pessoas contemplavam o critério estabelecido para participar do estudo. No entanto, apenas dez continuavam a residir no território adscrito da unidade de saúde. Todas as dez foram convidadas através de contato por chamada telefônica. Dessas, duas responderam estar impossibilitadas de participar na data agendada e duas, que haviam confirmado a participação, não compareceram no dia. Assim, seis pessoas, todas mulheres, de idade entre 30 e 62 anos, participaram do grupo focal.

Para a definição do número de grupos focais, os pesquisadores levaram em consideração que "em estudos exploratórios uma a dois grupos focais seriam suficientes"12 e "quando a população de interesse é relativamente homogênea e a questão de pesquisa é relativamente simples, um único grupo pode ser suficiente". ${ }^{12}$

Para a realização desta técnica de coleta de dados, foram utilizadas perguntas abertas, norteadoras, previamente concebidas pelo grupo de pesquisadores, que versavam sobre as ideias acerca dos problemas de saúde; o modo em que a história da pessoa foi abordada durante os atendimentos; a participação na elaboração do plano terapêutico e, por fim, a relação médico-pessoa.

Dois moderadores conduziram o grupo focal, na Unidade de Saúde da Família onde os sujeitos da pesquisa foram assistidos. Um dos pesquisadores, o principal, realizou anotações, e toda a discussão foi gravada em áudio, que posteriormente foi transcrito na íntegra. A duração total da atividade foi de 1 hora e 22 minutos. Os dados foram submetidos à análise de conteúdo, respeitando-se todas as etapas desta: a) pré-análise; b) exploração do material; e c) tratamento dos resultados obtidos com interpretação associada. ${ }^{14}$

Para buscar uma representação da realidade estudada, a interpretação dos dados ocorreu por triangulação da inferência dos pesquisadores. Dois participaram diretamente da coleta e um terceiro, envolvido durante todo o processo da pesquisa, intencionalmente não participou do grupo focal. Buscou-se, com isso, ampliar empiricamente a capacidade de compreensão acerca do fenômeno estudado.

Os resultados e a discussão são apresentados sob a perspectiva de três fontes: as narrativas (campo empírico), referenciadas pelo estado da arte (campo teórico) e as inferências dos pesquisadores (campo especulativo). Os nomes reais dos participantes foram substituídos por fictícios. ${ }^{15}$

A pesquisa foi desenvolvida conforme as normas preconizadas na Resolução do Conselho Nacional de Saúde/CNS número 466/12, que disciplina a pesquisa com seres humanos. Os autores assumiram todas as despesas do projeto e afirmam não possuírem conflitos de interesse de qualquer ordem. 


\section{Resultados e Discussão}

A análise das narrativas dos participantes do estudo sugere que as consultas conduzidas pelo MCCP associadas às sessões de acupuntura foram geradoras de diversos sentimentos nos usuários. Tais relatos dialogaram intensamente com os componentes do MCCP e com os princípios da MTC.

Emergiram dos participantes temas que versavam sobre emancipação, autoconhecimento, integralidade, vínculos e afetos. Os resultados foram sistematizados em três temas e quatro categorias (Quadro 1).

Quadro 1. Síntese dos temas e categorias.

\begin{tabular}{|ll|}
\hline Temas & Categorias \\
\hline Autoconhecimento e emancipação & A prática integrada do MCCP/MTC produzindo Rizomas \\
Integralidade & Unidade mente-corpo no contexto do cuidado \\
Vínculos e Afetos & Percepção de uma anatomia emocional \\
\hline
\end{tabular}

\section{Autoconhecimento e emancipação}

\section{Relação MCCP/MTC produtora de rizomas}

Rizoma é um termo que originalmente deriva da botânica. Em seu aspecto estritamente biológico se refere a um sistema de caules subterrâneos de plantas flexíveis que dão brotos e raízes adventícias em sua parte inferior. Realizam trocas estreitas que são praticamente indistinguíveis do solo circundante. ${ }^{16}$

Pelo fato de realizarem múltiplos processos de troca em um infinito interior, seu conceito foi adaptado por Deleuze e Guatarri de modo a representar um lugar de encontro de imprevisibilidades geradoras de novos começos, com relações horizontais sem começo nem fim, em um sistema de atalhos e desvios sem vias diretas e retas, centro ou periferias. ${ }^{17}$

Uma das participantes da pesquisa relata sua experiência de autoconhecimento e empoderamento advindo da comparação do tratamento atual com os acompanhamentos médicos pregressos permeados de desigualdades agora ressignificados:

"Havia aquela sensação de não poder falar na consulta. Eu sou só uma paciente. Aquela desigualdade. É uma desigualdade que existe, entende? É uma desigualdade que muito faz você se sentir inferior. Depois, com esse meu tratamento, eu posso dizer que eu mudei minha visão." (Clarice)

O rizoma funciona como um dispositivo de reprodução da realidade social partindo das relações dos sujeitos e de suas conexões interiores e com o mundo em diversos fluxos de intensidade, permitindo seu crescimento, fazendo novas conexões em qualquer momento do processo, visto que não possui início e nem fim. ${ }^{18}$

A medicina chinesa busca as relações da pessoa com a multiplicidade da natureza. $\mathrm{Na}$ acupuntura a intervenção objetiva realizar estímulo no organismo para que esse retome, através de conexões e autorregulações, seu estado de equilíbrio. ${ }^{19}$ 
Quando questionadas em relação à maneira que o tratamento com acupuntura as propiciou pensamentos relacionados com a saúde e com seus problemas de saúde, as Comunitárias Gilda e Clarice, respectivamente, disseram:

"Até a minha convivência dentro de casa com o meu marido mudou. A gente convive dentro de casa como dois irmãos, mas com mais seriedade, respeitando mais um ao outro. Os meus direitos são iguais aos dele e eu sei onde eu vou buscar meus direitos." (Gilda)

"Eu começo a entender que a minha crença é uma. Mas eu consigo respeitar e aceitar de forma respeitosa a de quem tiver do meu lado. Tem tolerância e respeito. Aprendi a valorizar as minhas raízes, mas sem entristecer se meu irmão de lado acredita em algo diferente do que eu. Isso é um ponto muito bom." (Clarice)

Os dois relatos trazem elementos de novas ligações estabelecidas a partir de conexões interiores que ocorrem em passagens subterrâneas do pensamento. Tanto na pessoa que fez ligações com a relação conjugal e com empoderamento quanto na que estabeleceu conexão do tratamento com suas crenças religiosas, e depois com o respeito coletivo, existe um fluxo de subjetividades que eclodem novos recomeços.

Um dos objetivos primordiais do MCCP é tentar identificar as situações que podem estar vinculadas a qualquer dimensão da existência da pessoa interferindo decisivamente na capacidade que ela tem de alcançar seus objetivos de vida. A partir desse mapeamento, parte-se para o trabalho de potencializar outros aspectos que contribuam para o autoconhecimento e equilíbrio da pessoa. ${ }^{20}$

Quando os sistemas entram em via de harmonização, a partir dos estímulos que foram realizados, entendemos que quem efetivamente produziu as transformações buscando novos padrões de regulação foi a própria pessoa. ${ }^{21}$ As conexões advindas desse processo são imprevisíveis tais como as de um rizoma.

\section{Integralidade}

\section{Unidade mente-corpo no contexto do cuidado}

Para a MTC, existe uma correlação direta entre nossas emoções, medos ou outros processos de consciência com os processos corporais. Separar corpo e mente contradiz o pensamento chinês, que, diferentemente de algumas vertentes do pensamento da medicina ocidental, não reduz ou segmenta o curso da vida. $O$ tratamento com acupuntura consegue acessar esse complexo unitário ocidentalmente dividido. ${ }^{19}$

O MCCP trabalha na perspectiva de se utilizar de sensibilidade integradora no contexto do cuidado. Nessa modalidade de abordagem, procura-se observar mente e corpo como um todo integrado de tal modo que separar alguma parte desse todo seria um erro, pois minimizaria ou até negaria a importância das outras partes. ${ }^{22}$

O método traz em seu cerne que essas divisões podem reforçar outros tipos de divisões na profissão, o que pode produzir uma prática médica carregada de impessoalidade, fragmentação e, em última análise, 
desumanização, que interfere profundamente no sentido de coletividade e cumplicidade interpessoal própria do contexto de cuidado. ${ }^{23}$

"Pior que é verdade, porque eu nunca pude imaginar que um tratamento desse vê como ser humano completo porque, assim, coisas que eu nunca tive coragem de fazer, nunca tive coragem de falar e agora, com esse tratamento, eu fui capaz de falar." (Gilda)

Essa fala de Gilda demonstra que, com esse tipo de abordagem, objetiva-se alcançar uma integralidade como a defendida pelo autor Rubem Matos, que a entende fazendo parte de uma imagemobjetivo potencializadora de autonomia. Para esse autor, se em uma visão utópica a integralidade pode parecer muitas vezes inalcançável, vê-la como uma imagem-objetivo fornece um horizonte temporal real e definido para se buscar transformação. ${ }^{24}$

Ratificando a ideia de unidade, Jou Eel Jia relata que na China clássica não se fazia e distinção entre matéria e espírito. A noção de alma como uma essência completamente espiritual e que se oporia ao corpo não existe no pensamento chinês. Eles não consideram que a alma dê vida ao corpo, mas que ela surge através de um enriquecimento da vida corporal. ${ }^{25}$

"A abordagem de tentar mostrar que havia algo por trás daquela dor lombar. Não é só essa dor, não é só esse problema ósseo. Existem outras coisas por trás, que me fizeram refletir. Existem outros sentimentos e relações que fazem com que também esse problema seja bem mais sentido, que, no caso, é a dor.” (Joana)

A acupuntura não aborda somente os aspectos funcionais dos pontos de acupuntura, mas também as diferentes funções dos canais de energia. A energia precede a forma física e, portanto, as estruturas físicas teciduais. Reconhecer esse estado energético de órgãos e vísceras potencializa a noção de unidade mente-corpo que a medicina tradicional chinesa carrega. ${ }^{26}$

"Essa consciência de que somos energia vem bem mais forte, porque, quando as agulhas são colocadas, dá um choque terrível. Bem forte. Então, essa consciência de que somos energia e que somos parte desse universo, não é? Que tudo é energia e que a gente adoece exatamente quando há uma alteração na energia, na condução dessa energia." (Violeta)

\section{Percepção de uma anatomia emocional}

Outro entendimento importante parece estar na ideia de que, no decorrer de nossa existência, a vida vai produzindo formas, que fazem parte de um processo de organização que dá corpo às emoções, pensamentos e experiências, de modo a lhes fornecer uma estrutura. A forma humana é marcada pelo amor e pelas decepções, de tal modo que, se pudéssemos fotografar nossa vida projetando-a quadro a quadro, perceberíamos que no fundo somos uma sequência móvel de emoções variadas. ${ }^{27}$ 
A partir desse entendimento, o autor Stanley Keleman produziu um conceito que chamou de anatomia emocional, para refletir que o registro de nossas experiências possui um componente corporal, que gera infinitas modalidades e tonalidades no sentimento de estar vivo. Ao fazer isso, o autor nos apresenta por uma outra vertente a existência da unidade mente-corpo. ${ }^{28}$

A usuária Mercedes traz esse entendimento que versa sobre a percepção de um registro corporal ao citar suas experiências durante as sessões de acupuntura:

"Então, isso tudo me ajuda a trazer essa consciência. Várias vezes, passei por sessões de acupuntura em que fui compreender a causa daquela dor, daquele incômodo, no braço, no pé, nas costas... Fui compreendendo onde é que começou essa história, o que foi que ocasionou aquela desarrumação, aquela dor, aquela tensão e que registro tinha ficado ali no meu corpo." (Mercedes)

Para o MCCP, alguns casos revelam a complexidade da relação existente entre mente-corpo, passado e presente, e entender a jornada de vida das pessoas como um tapete tecido por inúmeros eventos que podem deixar as mais variadas cicatrizes facilita a promoção de um cuidado centrado na pessoa. ${ }^{23}$

Ao se referir a uma experiência de sensação física posteriormente vinculada a uma questão de opressão percebida no momento de uma sessão de acupuntura, Violeta disse:

"Teve uma experiência em que eu senti, eu fiquei, assim, um pouco fora. Não aquela elevação. E depois eu fui sentindo como se tivesse desatando um nó no meu braço. Depois comentei 'poxa, desatou um nó no meu braço!' $E$ foi isso mesmo que aconteceu: desatou um nó no meu braço." (Violeta)

Anatomia emocional significa entender pele, músculos, órgãos, ossos e experiências de vida como constituintes de um único complexo que nos faz ser quem somos. Fugindo com isso de conceitos baseados em algo que seja ideal. A preocupação mais importante para o indivíduo é a de reconhecer a si mesmo para funcionar de um modo que traga equilíbrio, independentemente de padrões pré-estabelecidos socialmente. ${ }^{27}$

\section{Vínculos e Afetos}

\section{MCCP E MTC como reconfiguradoras do Circuito dos Afetos}

O filósofo Vladimir Safatle contribui com o estudo apresentando a ideia de pensarmos nossas relações a partir de um circuito dos afetos. Para o autor, o afeto que hoje constrói os nossos vínculos sociais é o do medo. O medo é o afeto mais plástico que existe, se transmuta por todos os lados, o que contribui para limitar nossa capacidade de produzir outros afetos. Ficamos presos em um circuito que nos limita e nos gera impotência e afetos paralíticos. ${ }^{29}$

Precisamos, portanto, pensar em quais afetos mobilizam. Enquanto as pessoas forem afetadas da mesma forma agirão da mesma maneira. Logo, há a necessidade de afetações diferentes para a geração de movimentos novos. ${ }^{29}$ 
Com o MCCP, avalia-se que o passado das pessoas pode muitas vezes servir como uma espécie de assombração geradora de uma imobilidade na capacidade de agir, e que esses problemas do passado podem ser exorcizados por uma escuta acolhedora da história de vida da pessoa. ${ }^{23}$

Esse medo que paralisa e a percepção dele é descrito por Violeta:

"Acho que mais de uma vez eu vim pedir ajuda. Para dizer 'olha, tem uma crise de medo aqui que eu não sei de onde vem'. Eu preciso trabalhar esse medo, não é? E me ajudou a trabalhar o medo, que era exatamente o medo que me impedia de seguir mais adiante, de enxergar o novo caminho. Medos que foram guardados sei lá quando." (Violeta)

Safatle dialoga com a fala de Violeta por acreditar que não será com os mesmos corpos construídos por afetos que até agora sedimentaram nossa subserviência que seremos capazes de criar realidades políticas impensadas. Nesse sentido, o autor defende que mais do que novas ideias, precisamos de fato é de um outro corpo, concluindo que nunca haverá nova política, com os velhos sentimentos de sempre. ${ }^{29}$

Cabe avaliar como produzir novos afetos. Se nada muda pelo fato das pessoas continuarem a serem afetadas da mesma forma, como recompor circuito de sentimentos paralisantes em uma outra chave? Como se trabalhar com a ideia de uma negatividade transmutável?

O relato de Gilda pode servir de exemplo ao sugerir o surgimento de afetos que impulsionam, que reconfiguram identidades:

"Mas me fez um bem, parece que me fez mais nova. Como Jesus Cristo, quando aconteceu na minha vida, porque eu sou católica, e tenho orgulho de mim por ser católica, mas eu nunca tive coragem antes, de chegar pra me confessar. Por isso, eu passei mais de 30 anos sem me confessar. Por que eu não tinha coragem de falar o que eu sentia. E falei pro médico. Impressionante!" (Gilda)

Na visão da MTC, disponibilizar energia para fortalecimento de potências de vida deve ser um dos princípios orientadores de quem trabalha com acupuntura. Quando produzimos estímulos com as agulhas, estamos auxiliando o organismo a constituir suas próprias linhas de fuga, pois existe uma disponibilização de energia do próprio organismo para que ele busque alternativas que fortaleçam seu melhor ritmo de produção. ${ }^{21}$

Essa linha de fuga que fornece respostas é observada na fala de uma das participantes:

"A acupuntura nos traz para a gente mesmo. É isso que eu senti. Eu descobri onde que começou, de onde vem aquela dor. Eu pergunto: o que é que essa dor quer me dizer, né? Então vem a resposta." (Violeta) 
$\mathrm{Na}$ acupuntura, a intervenção é orientada para que o organismo receba estímulos que favoreçam a retomada de sua mais ampla capacidade de produção, buscando o caminho da autorregulação de modo a engendrar uma reorganização do sistema corporal que combata qualquer possibilidade de paralisação do pensamento. ${ }^{19}$

Clarice ratifica essa melhora após as sessões com acupuntura:

"Eu tenho que dizer que a acupuntura me trouxe uma nova forma de me enxergar. De enxergar realmente o que eu gosto, o que eu sou. Não só os meus problemas, que muitas vezes me deixavam presa." (Clarice)

O MCCP versa sobre a necessidade do médico conhecer a estrutura da personalidade de cada pessoa, incluindo seus mecanismos de defesa muitas vezes automáticos e inconscientes. Essa percepção associada ao entendimento de que muitas pessoas estão presas em circuito dos afetos permeados pelo medo que estagna pode favorecer a um olhar diferente para o usuário que se mostre fechado ao diálogo.

A fala da entrevistada Clarice ao se referir a como sua sogra se sentiu e o que disse ao ser consultada pelo mesmo médico cabe bem a esse contexto:

"Ela citou que é algo que não acredita, que não vê solução nisso. 'Cheguei numa consulta com ele, tentei conversar com ele, mas um homem risonho. Um homem risonho'.

Eu olhei assim pra ela. Não segui em frente a conversa porque o que é que minha sogra espera de um atendimento? Uma coisa padrão, que a gente citou aqui. Me parece que existe uma certa visão que um médico mais velho, fechado, ele passa essa experiência, sabe? Existia uma resistência em eu conversar com a minha família sobre isso, entende?" (Clarice)

O MCCP e a MTC, por meio da acupuntura, aparentemente podem agir em uma micropolítica que atua nos corpos reconfigurando o circuito dos afetos em um desenho que transmuta a negatividade produtora de afetos inertes, de modo a produzir novas formas de afetação e, consequentemente, de potência existencial transformadora.

\section{Limitações do estudo}

Pensando no que se refere às limitações do estudo, a pesquisa não conseguiu identificar muitos fatores que se relacionassem seguramente com características negativas advindas da relação entre o MCCP e as sessões de acupuntura. $O$ fato de terem sido entrevistadas somente pessoas que já tinham realizado várias sessões pode ter atuado como um separador natural daqueles que não retornaram por não terem se sentido bem após a primeira abordagem. É preciso se pensar em outros desenhos de estudo que permitam atingir esses usuários na perspectiva de entender melhor os aspectos negativos dessas experiências.

Apesar de não haver consenso quanto à escolha de participantes para compor um grupo para que o mesmo seja heterogêneo ou homogêneo, devendo essa decisão se basear na intenção da pesquisa, ${ }^{30}$ o fato das participantes da pesquisa serem todas mulheres foi identificado como uma segunda limitação deste estudo. 
Se por um lado a pesquisa qualitativa pressupõe tentar representar a realidade subjacente que pode ser estudada, ${ }^{10}$ por outro, muito embora a neutralidade da investigação seja impossível, no conduzir da pesquisa que se pretenda científica, o pesquisador deve adotar métodos com técnicas demonstráveis por procedimentos lógicos. ${ }^{31} \mathrm{O}$ fato do pesquisador principal participar como condutor do grupo focal, e ter sido ele o cuidador dos sujeitos da pesquisa, pode ser considerado um fator limitante deste estudo, uma vez que as nuances das opiniões expressas pelos sujeitos da pesquisa podem estar relacionadas não apenas ao procedimento de seleção dos participantes, mas também à mistura do profissional cuidador/pesquisador.

\section{Considerações finais}

A partir da perspectiva dos usuários, constata-se que consultas que utilizam o MCCP em conjunto com a MTC estreitam a relação médico-pessoa em um campo que transcende a divisão dualística entre mente e corpo, fortalece a natureza da MFC dentro de um paradigma integralista. As percepções relatadas pelos participantes da pesquisa sobre este tipo de abordagem sugerem o quanto a especialidade pode se utilizar dos conhecimentos advindos de outras racionalidades para potencializar o cuidado fornecido pela APS.

As práticas integrativas essencialmente buscam atender às demandas de atenção e cuidados dos usuários, criando um percurso de tratamento permeado de singularidades geradoras de autoconhecimento para todos os envolvidos no processo do cuidado.

\section{Contribuição dos autores}

De acordo com a Taxonomia das Funções do Colaborador (CRediT), os autores exerceram as seguintes colaborações:

Santos ACD, Correia IB e Silva RC: Conceptualization; Data curation; Formal analysis; Funding acquisition; Investigation; Methodology; Project administration; Resources; Visualization; Writing - original draft; Writing - review \& editing.

Santos ACD e Silva RC: Investigation.

Correia IB e Silva RC: Supervision.

\section{Agradecimentos}

"Para todos que vivem a medicina de família e comunidade como bússola do coração"

\section{Conflito de interesses}

Declaram não haver.

\section{Referências}

1. Brasil. Ministério da Saúde. Política Nacional de Práticas Integrativas e Complementares no SUS. Brasília: Ministério da Saúde; 2006.

2. Cunha GT. A construção da clínica ampliada. 3ª ed. São Paulo: HUCITEC; 2010.

3. Brasil. Ministério da Saúde. Formação em Auriculoterapia para profissionais de Saúde da Atenção Básica. Brasília: Ministério da Saúde; 2016. 
4. Lopes JMC. Consulta e Abordagem Centrada na Pessoa. In: Gusso G, Lopes JMC, eds. Tratado de Medicina de Família e Comunidade. Porto Alegre: ARTMED; 2012. p. 113-23.

5. McWhinney IR. A evolução do método clínico. In: Stewart M, Brown JB, Weston WW, McWhinney IR, McWilliam CL, Freeman TR. Medicina Centrada na Pessoa. Transformando o Método Clínico. 3를. ed. Porto Alegre: Artmed; 2017. p. 17-30.

6. Tesser CD, Barros NF. Medicalização social e medicina alternativa e complementar: pluralização terapêutica do Sistema Único de Saúde. Rev Saúde Pública. 2008;42(5):914-20. https://doi.org/10.1590/S0034-89102008000500018

7. White AC, Cummings M, Filshie J. Acupuntura Tradicional Chinesa Reinterpretada. In: White AC, Cummings M, Filshie J. Introdução a Acupuntura Médica Ocidental. São Paulo: Roca; 2013. p. 89-106.

8. Luz MT, Barros NF, orgs. Racionalidades médicas e práticas integrativas em saúde - Estudos teóricos e empíricos. Rio de Janeiro: CEPESC/UERJ/IMS/ABRASCO; 2012.

9. Freitas FPP. Acupuntura no contexto do atendimento aos usuários com dor crônica na atenção primária à saúde do município do Rio de Janeiro [dissertação]. Rio de Janeiro: Escola Nacional de Saúde Pública Sergio Arouca, Fundação Oswaldo Cruz; 2015.

10. Mays N, Pope C, orgs. Pesquisa qualitativa na atenção à saúde. 3ª ed. Porto Alegre: Artmed; 2009.

11. Gondin SMG. Grupos focais como técnica de investigação qualitativa: desafios metodológicos. Paidéia. 2002;12(24):149-61.

12. Vingilis E, Yildirim-Yenier Z, Vingilis-Jaremko L, Seeley J, Wickens CM, Grushka DH, et al. Young male drivers' perceptions of and experiences with YouTube videos of risky driving behaviours. Accid Anal Prev. 2018;120:46-54. https://doi.org/10.1016/j.aap.2018.07.035

13. Pires A. Amostragem e pesquisa qualitativa: ensaio teórico e metodológico. In: Poupart J, Deslauriers JP, Groulx LH, Lapemère A, Mayer R, Pires AP, orgs. A pesquisa qualitativa: enfoques epistemológicos e metodológicos. 4ª ed. Petrópolis: Vozes; 2014 . p. $155-214$.

14. Bardin L. Análise de conteúdo. Lisboa: Edições 70; 2011.

15. Paillé P, Mucchielli A. L’analyse qualitative en sciences humaines et sociales. Paris: Armand Colin; 2012.

16. Guattari F, Rolnik S. Micropolítica: Cartografias do Desejo. 4aㅡ ed. Petrópolis: Vozes; 1996.

17. Deleuze G, Guattari F. Mil Platôs. Volume 1. São Paulo: Editora 34; 1995.

18. Carvalho MN, Franco TB. Cartografia dos caminhos de um usuário de serviços de saúde mental: produção de si e da cidade para desinstitucionalizar. Physis. 2015;25(3):863-84. https://doi.org/10.1590/S0103-73312015000300010

19. Wallner FG. Medicina Tradicional Chinesa: Um modo alternativo de pensar. 1르 ed. São Paulo: Editora Pensamento; 2011.

20. Stewart M, Brown JB, McWilliam CL, Freeman TR, Weston WW. O primeiro componente: explorando a saúde, a doença e a experiência da doença. In: Stewart M, Brown JB, Weston WW, McWhinney IR, McWilliam CL, Freeman TR. Medicina Centrada na Pessoa. Transformando o Método Clínico. $3^{\underline{a}}$ ed. Porto Alegre: Artmed; 2017.

21. Caleri D. Medicina Chinesa Viva: Arte e Singularidade. 1ª ed. São Paulo: Ícone Editora; 2013.

22. Freeman T. Método Clínico. In: Manual de Medicina de Família e Comunidade de McWhinney. 3ª ed. Porto Alegre: Artmed; 2010. p. 151204.

23. Brown JB, Weston WW. O segundo componente: entendendo a pessoa como um todo - seção 1 - o indivíduo e a família. In: Stewart M, Brown JB, Weston WW, McWhinney IR, McWilliam CL, Freeman TR. Medicina Centrada na Pessoa. Transformando o Método Clínico. $3^{\text {a }}$ ed. Porto Alegre: Artmed; 2017.

24. de Mattos RA. Os sentidos da Integralidade: Algumas reflexões acerca de valores que merecem ser defendidos. In: Pinheiro R, de Mattos RA, eds. Os sentidos da Integralidade na atenção e no cuidado à saúde. $8^{\underline{a}}$ ed. Rio de Janeiro: CEPESC-IMS/UERJ-ABRASCO; 2009. p. 43-68.

25. Jia JE. Ch'an Tao - Conceitos Básicos: Medicina Tradicional Chinesa, Lien Ch’i e Meditação. 2ª ed. São Paulo: Ícone Editora; 2004.

26. Yamamura Y. Acupuntura Tradicional: A arte de inserir. 2ª ed. São Paulo: Editora Roca; 2003.

27. Keleman S. Anatomia Emocional. 5ª ed. São Paulo: Summus Editorial; 1992.

28. Keleman S. Padrões de Distresse: Agressões emocionais e forma humana. $2^{\underline{a}}$ ed. São Paulo: Summus Editorial; 1992.

29. Safatle V. O Circuito dos Afetos: Corpos políticos, desamparo e o fim do indivíduo. 1aㅡ ed. São Paulo: Cosac Naify; 2015.

30. Crabtree BF, Miller WL, eds. Doing Qualitative Research. London: Sage Publications; 1992.

31. Oliveira L. Neutros \& neutros. Humanidades. 1988;5(19):122-7. 